\title{
A practical application of reduced-copper antifouling paint in marine biological research
}

\author{
Andrea S. Jerabek ${ }^{\text {Corresp., }}{ }^{1,2}$ ， Kara R. Wall ${ }^{2}$, Christopher D. Stallings ${ }^{2}$ \\ ${ }^{1}$ College of Science, Northeastern University, Boston, Massachusetts, United States \\ 2 College of Marine Science, University of South Florida, St. Petersburg, Florida, United States \\ Corresponding Author: Andrea S. Jerabek \\ Email address: andrea.jerabek1@gmail.com
}

Biofouling of experimental cages and other field apparatuses can be problematic for scientists and has traditionally been addressed using frequent manual removal (e.g., scraping, scrubbing). Recent environmental restrictions and legislative changes have driven the development of less hazardous antifouling products, making antifouling paint a potential alternative option to manual removal. Consequently, the viability of using these newly developed products as a replacement for the manual cleaning of exclusion cages was experimentally investigated. There were six treatments tested, comprising three with settlement tiles in experimental cages coated with antifouling paint, two with settlement tiles in unpainted experimental cages, and one cage-free suspended tile. The three antifouling treatments comprised two reduced-copper paints $\left(21 \% \mathrm{Cu}_{2} \mathrm{O}\right.$ and $\left.40 \% \mathrm{Cu}_{2} \mathrm{O}\right)$ and one copper-free, Econea ${ }^{\circledR}$-based paint (labeled "ecofriendly"). Antifouling paints were assessed for performance of preventing fouling of the cages and whether they elicited local effects on settlement tiles contained within them. All three paints performed well to reduce fouling of the cages during the initial six weeks of the experiment, but the efficacy of "ecofriendly" paint began to decrease during an extended deployment that lasted 14 weeks. The macrofouling community composition, biomass, and percent cover of settled organism on tiles within cages treated with copper-based paints ( $21 \%$ and $40 \%$ concentrations) were indistinguishable from tiles within the manually scrubbed cages. In contrast, settlement to tiles from the "ecofriendly" treatment was different in composition of macrofouling communities and lower in biomass, suggesting the presence of local effects and therefore rendering it unsuitable for use in settlement experiments. The results of this study suggest that reduced-copper paints have the potential to serve as an alternative to manual maintenance, which may be useful for deployments in locations that are difficult to access on a frequent schedule. 


\section{A practical application of reduced-copper antifouling paint 2 in marine biological research}

3

4 Andrea S. Jerabek ${ }^{1,2}$, Kara R. Wall ${ }^{2}$, Christopher D. Stallings ${ }^{2}$

$5{ }^{1}$ College of Science, Northeastern University, Boston, Massachusetts, USA

$6{ }^{2}$ College of Marine Science, University of South Florida, St. Petersburg, Florida, USA

7

8 Corresponding Author:

9 Andrea Jerabek ${ }^{1,2}$

105821 Jasmine Circle, East Syracuse, New York, 13057, USA

11 Email address: andrea.jerabek1@gmail.com

12

13

14

15

16

17

18

19

20

21

22

23

24

25 


\section{INTRODUCTION}

27 Biofouling has historically been an implacable source of frustration for mariners (Woods Hole

28 Oceanographic Institution, 1952). Likewise, biofouling of gear used in field experiments (e.g.,

29 predator exclusion cages) can be of concern for scientists. The numerous negative effects of

30 biofouling include reduced water flow, decreased oxygen levels, and increased weight and drag

31 of infrastructures (Fitridge et al., 2012). Traditionally, scientific studies have used manual

32 techniques to remove biofouling, such as scrubbing and scraping (Smith, Smith \& Hunter, 2001;

33 Jompa \& McCook, 2002; Burkepile \& Hay, 2010; Burkholder et al., 2013). While manual

34 biofouling removal can be effective, it can also result in experimental disturbances, which could

35 potentially skew study results (Dobretsov, Williams \& Thomason, 2014). Manual removal also

36 requires frequent upkeep and monitoring (often at least twice per week). Consequently, it may be

37 neither time- nor cost-effective for scientists to conduct experiments in locations where their

38 infrastructures cannot be maintained on this frequent schedule.

39 One potential alternative to manual removal of biofouling organisms is the use of

40 antifouling paints. Although antifouling paints were originally developed to prevent biofouling

41 on vessel hulls, the technology is currently used in a multitude of commercial industries and

42 research endeavors. For example, antifouling paints are frequently used by the aquaculture

43 industry to eliminate the tremendous effort required to bring infrastructures on-shore for manual

44 cleaning and maintenance (Simpson, Spadaro \& O’Brien, 2013). Additionally, antifouling paints

45 are often used for docks, buoys, transducers, and site indicators. Currently, cuprous oxide is the

46 most widely used antifouling biocide. However, there has been mounting evidence illustrating

47 the negative environmental consequences of elevated copper levels on marine organisms (Yebra,

48 Kiil \& Dam-Johansen, 2003; Thomas \& Brooks, 2010; Guardiola et al., 2012; Qi et al., 2013), 
49 resulting in the development of antifouling paints with lower copper concentrations.

50 Additionally, recent legislative evaluations of copper-based paints have facilitated the emergence

51 and acceptance of Econea ${ }^{\mathrm{TM}}$, an organic biocide, as the "ecofriendly" substitute to cuprous oxide.

52 However, there is limited information regarding the toxicity and long-term environmental effects

53 of Econea ${ }^{\mathrm{TM}}$ (Holman et al., 2011).

54 This study tested the efficacy of using the newly developed antifouling paints as an

55 alternative to manually cleaning experimental apparatuses deployed in situ. Specifically, a field

56 experiment was conducted to determine whether two levels of reduced-copper paints, and one

57 copper-free, ecofriendly paint can be used for extended deployments of predator exclusion cages

58 that house settlement tiles. Furthermore, antifouling paints were examined to determine if they

59 elicited local effects on settlement to the tiles.

60

61 MATERIAL AND METHODS

62 Experimental design

63 To test the efficacy of using antifouling paints as an alternative to manual experimental cage

64 maintenance, a field experiment was conducted to compare the macrofouling community

65 composition, biomass accumulation, and percent cover of settlement tiles placed inside predator

66 exclusion cages (Fig. 1). The experiment included six levels of a caging treatment: (1) "no-

67 scrub" (no paint and no manual maintenance), (2) "scrub" (no paint, scrubbed clean twice

68 weekly as in traditional manual maintenance), (3) “ecofriendly" paint (blue Hydrocoat Eco

69 Ablative Antifouling Paint ${ }^{\circledR}$ treatment), (4) “21\% $\mathrm{Cu}_{2} \mathrm{O}$ ” paint (blue “low-copper conc.” CPP

70 Ablative Antifouling Paint ${ }^{\circledR}$ treatment), (5) “40\% $\mathrm{Cu}_{2} \mathrm{O}$ ” paint (blue "medium-copper conc."

71 Horizons Ablative Antifouling Bottom Paint ${ }^{\circledR}$ treatment), and (6) "no-cage control" (suspended 
72 tile without a cage). Each painted cage received two hand-painted coats of a blue ablative

73 antifouling paint, as instructed by the manufacturer, to ensure consistent thickness and to

74 eliminate any potential experimental artifacts of color. The predator exclusion cages were 21.5

$75 \mathrm{~cm}(1) \times 10.6 \mathrm{~cm}(\mathrm{w}) \times 21.5 \mathrm{~cm}(\mathrm{~h})$ and constructed of Vexar, a pre-galvanized, PVC-covered

$760.064 \mathrm{~cm}$ metal mesh. The ceramic settlement tiles $(11.5 \mathrm{~cm}(\mathrm{l}) \times 11.5 \mathrm{~cm}(\mathrm{w}) \times 0.6 \mathrm{~cm}(\mathrm{~h}))$ were

77 suspended within the cage via cable ties threaded through three $31.7 \mathrm{~mm}^{2}$ drilled holes. Lost

78 surface area due to drill holes was accounted for in percent cover calculations. A $5 \mathrm{~cm}$ buffer was

79 maintained between the tile and cage frame to ascertain if antifouling paint ablation, or "wearing

80 off", affected settlement to the tiles without direct contact. Sixty experimental units ( $\mathrm{n}=10$ per

81 treatment level) were deployed in Bayboro Harbor, St. Petersburg, Florida, U.S.A. on July $30^{\text {th }}$,

822015 (day 0) with a 0.5 meter distance between cages to minimize cross contamination of

83 antifouling paint. Cages were randomly dispersed within a grid design. The experiment

84 concluded six weeks later on September $10^{\text {th }}, 2015$ (day 42). On day 42 of the primary

85 experiment, all tiles received final measurements (see below), cages were scrubbed (where

86 applicable according to assigned treatment level), and all cages were returned to the water where

87 they remained untouched for an additional 62 days to qualitatively investigate the longer-term

88 performance of the antifouling paints on the cage materials (i.e., 104 days total).

89 During the primary six-week experiment, tiles were removed from their cages once per

90 week, weighed to measure biomass, and photographed for subsequent macrofouling community

91 composition and percent cover analyses. Following data collection, tiles were promptly re-

92 suspended within the cages and returned to the water. Initial tile masses were subtracted from all

93 biomass measurements to obtain the weight of the fouling organisms on the tiles. Twice per

94 week, the scrubbed cages were removed from the water for 15 minutes to provide time to be 
95 scrubbed with a plastic bristle brush. To control for the time the scrubbed cages were out of the

96 water, all non-scrubbed cages were also removed from the water for 15 minutes, thus ensuring

97 uniformity across all treatments. Cages were inspected for performance throughout the duration

98 of the experiment and photographed post-completion.

\section{Data analysis}

100 Coral Point Count with Excel extensions (CPCe) version 4.1 software (Kohler \& Gill, 2006) was

101 used to analyze tile photographs for macrofouling community composition. Each photograph

102 was overlaid with 60 randomly stratified points. The organisms underneath each point were

103 visually identified, after which the total number of points per species was divided by 60 to

104 determine the percent cover of each organism per tile. The percent cover estimates of each

105 species per tile were analyzed statistically to determine whether macrofouling community

106 composition differed among treatments (See Statistical analysis). Algae were clumped into a

107 generalized "turf algae" functional group for macrofouling community composition analysis

108 because photograph resolution was insufficient to distinguish among species.

109 The combined percent cover of all the fouling organisms on the tiles was analyzed using

110 the software Image J (Version 1.48V). ImageJ was chosen because of its ability to the measure

111 the area of atypical shapes on a photograph (i.e., biofouling on a settlement tile). To accomplish

112 this, the image type of each tile photograph was changed to 8-bit, creating a grayscale image.

113 Following this transformation, the image threshold was adjusted to create a strong contrast

114 between the settling organisms and the ceramic tile. The fouling organisms were then visually

115 distinct from the tile and the atypically shaped and discontinuous areas of the fouling organisms

116 on the tiles could be selected and quantified by ImageJ. The area of the fouling organisms

117 measured by ImageJ was then divided by the total relative area of the ceramic tile and multiplied 
118 by 100 to estimate overall percent cover of fouling organisms per tile.

\section{Statistical analysis}

120 Macrofouling community composition analysis was completed via nonmetric multidimensional

121 scaling (nMDS) in the statistical software program Primer using the Bray-Curtis (Sorensen)

122 distance matrix. A PERMANOVA and subsequent pairwise comparisons were conducted on the

123 percent cover data to determine whether macrofouling community composition differed among

124 treatments. Statistical analyses of tile biomass and total percent cover were completed separately

125 using the R statistical software programming environment (version 3.1.1). Tile biomass at the

126 conclusion of the study (i.e., week six) was log transformed (Sokal \& Rohlf, 1981), and

127 normality and homogeneity of the variance were confirmed via Shapiro-Wilk normality test and

128 Levene's Test for homogeneity of variance, respectively. Separate one-way analyses of variances

129 (ANOVA, alpha level $\mathrm{p}=0.05$ ) were conducted to test whether tile biomass and percent cover

130 differed among treatments by day 42 (i.e., completion of the experiment). Pairwise Tukey HSD

131 post-hoc tests were then conducted on significant main effects to test for differences in tile

132 biomass and percent cover between treatment pairs.

133

\section{RESULTS}

\section{Antifouling paint performance}

136 Antifouling paint performance on the cages was consistent for the copper-based paints

137 throughout the experiment. No more than three barnacle recruits were observed to be growing on

138 the cages at the completion of the 42-day study. The ecofriendly paint had a similar antifouling

139 performance with only few barnacles present on the cage frames. However, a thin algal slime

140 was also observed on some of the cages treated with the ecofriendly paint. In contrast, unpainted, 
141 no-scrub cages quickly accumulated an algal slime (7-14 days), subsequently providing the

142 foundation for macroalgae, barnacles, and other organisms to settle. The lack of scrubbing on the

143 unpainted, no scrub cages, allowed for the uninterrupted development of fouling communities

144 that likely inhibited flow through to the cages and affected settlement to the tiles. As expected,

145 the unpainted, scrubbed cages remained free of fouling organisms due to the frequent

146 maintenance performed throughout the study. After the additional two months of deployment

147 (following the primary, six-week experiment), there was notable divergence in performance

148 between the copper-based and ecofriendly antifouling paint treatments. Specifically, the copper-

149 based paints had developed a thin algal slime that easily washed off. Conversely, the ecofriendly

150 paint had a dense algal turf on the top of the cages accompanied by algal, barnacle, and hydroid

151 growth on the cage sides and supporting zip ties.

\section{Macrofouling community composition on tiles}

153 Over the six weeks of data collection, five different marine organism groups settled on the tiles:

154 barnacles (Amphibalanus amphitrite; C Darwin), tubeworms (Hydroides spp.), oysters

155 (Crassostrea virginica; JF Gmelin), mussels (Perna viridis; C Linneaus and Geukensia

156 granosissima; GB Sowerby III), and various algal species (turf algae)(Table 1). The first

157 organisms to colonize (barnacles, tubeworms, and turf algae) were present by day 7. Oyster

158 recruits appeared on the tiles enclosed by the cages with no-scrub, scrub, and $40 \% \mathrm{Cu}_{2} \mathrm{O}$ paint

159 treatments by day 28 , the ecofriendly and $21 \% \mathrm{Cu}_{2} \mathrm{O}$ paint treatments by day 35 , and the no-cage

160 control by day 42 (Fig. 2). Mussel recruits were observed by day 21 on the no-scrub and

161 ecofriendly treatments, but never accounted for more than $2 \%$ cover in any of the treatment

162 levels throughout the experiment (Table 1). By day 42 barnacle percent cover was similar across

163 treatments ranging from $80 \%$ to $100 \%$ cover. The ecofriendly painted and no-cage treatments 
164 had the largest percent covers of tubeworms and algae settled on the tiles. Percent cover of

165 oysters was above $10 \%$ only in the no-scrub treatment, remaining below $5 \%$ in all other

166 treatments (Fig. 2).

167 Percent cover was partitioned by species, and analyzed for the macrofouling community 168 composition. By day 42, macrofouling community composition was similar for the scrub, 21\%

$169 \mathrm{Cu}_{2} \mathrm{O}$ paint, and $40 \% \mathrm{Cu}_{2} \mathrm{O}$ paint treatments (PERMANOVA, $\mathrm{p}>0.05$; minimum convex

170 polygon A in Fig. 3). However, the ecofriendly paint, no-scrub, and no-cage control treatments

171 all formed distinct clusters in multivariate space (PERMANOVA, $p<0.05$, minimum convex

172 polygons B, C, D in Fig. 3, respectively).

\section{Biomass on tiles}

174 By day 42 (i.e., completion of the experiment), there were distinct differences in biomass of 175 settled organisms on the tiles across treatments (ANOVA, $F_{(5,54)}=54.47, p<0.001$, Fig. 4).

176 Biomass of tiles from cages that were scrubbed and those coated with either $21 \% \mathrm{Cu}_{2} \mathrm{O}$ paint or

$17740 \% \mathrm{Cu}_{2} \mathrm{O}$ paint were not different from each other (Tukey HSD tests, $\mathrm{p}>0.05$ ), and

178 accumulated the highest mean (SE) biomass of 480.2g ( \pm 11.5 ; cluster A in Fig. 4). The average

179 biomass on the tiles enclosed by the three aforementioned treatments was $37.7 \%$ higher than tiles

180 enclosed by cages treated with ecofriendly paint (348.7g \pm 9.7; letter B in Fig. 4), 87.6\% higher

181 than the no-scrub treatment $(255.9 \mathrm{~g} \pm 7.1$; letter $\mathrm{C}$ in Fig. 4), and 124.1\% higher than the no-cage

182 treatment $(214.2 \mathrm{~g} \pm 5.9$; letter $\mathrm{D}$ in Fig. 4). The ecofriendly paint treatment on average had the

183 next highest biomass accumulation, which was higher than both the no-scrub (Tukey HSD, p <

1840.001 ) and no-cage treatments (Tukey HSD, $\mathrm{p}<0.001$ ). Biomass accumulation to the no-cage

185 tiles was lower than that to no-scrub tiles (Tukey HSD, $\mathrm{p}=0.005$ ), presumably due to post-

186 settlement predation on the un-caged tiles (e.g., herbivory, molluscivory). 
Although the additional biomass accumulation on tiles was not quantified after the cages

188

189

190

191

192

193

194

195

196

197

198

199

200

201

202

203

204

205

206

207

208

209

were left unmaintained for the 62 days following the six-week study, interesting patterns were

noted. For the cages with the copper-based paints, additional growth and settlement of organisms

resulted in accumulation of growth that completely filled the cages, bringing the fauna in contact

with the painted frame (Fig. 5). These cages were generally observed to be full of oysters that

were dislodged from the tiles. Conversely, the organisms in the ecofriendly painted cages

remained constrained to the tiles, and the growth did not come into contact with the painted

frames. In both unpainted treatments (i.e., scrub and no-scrub), barnacles were found growing on the tiles and cage frames themselves due to the absence of antifouling paint.

\section{Percent cover on tiles}

All treatments except the ecofriendly paint and no-cage control had a mean percent cover of $80 \%$ cover by day 14 and $100 \%$ by day 21 (Fig. 6). The differences in percent cover of the ecofriendly and no-cage control treatments compared to the other four treatments emerged by day 14 of the study $\left(\right.$ ANOVA, $\mathrm{F}_{(5,54)}=9.15, \mathrm{p}<0.001$; Fig. 6). No significant difference of percent cover on tiles was observed between ecofriendly paint and the no-cage treatment (Tukey HSD, $p=0.725)$, but both were less than all other treatments (Tukey HSD, $\mathrm{p}<0.05$ ). By day 21 , the ecofriendly paint treatment increased to $100 \%$ cover while the no-cage treatment remained as the only one without complete coverage of growth on the tiles (Fig. 6). The significant difference between the no-cage treatment and the remaining treatments remained through the completion of the experiment (Tukey HSD, $\mathrm{p}<0.05$ ). However, percent cover on tiles enclosed by unpainted cages that were not scrubbed had decreased by day 42 , and were not significantly different than the nocage tiles (Tukey HSD, $\mathrm{p}=0.21$ ). 


\section{DISCUSSION}

211 Using a controlled, six-week long field experiment, it was determined that the macrofouling

212 community composition, biomass accumulation, and percent cover of settlement to tiles inside

213 cages treated with reduced copper-based paints were indistinguishable from tiles inside

214 unpainted cages that were scrubbed twice per week. Thus, there were no apparent local effects of

215 the copper-based paints on biomass or macrofouling community composition of settled

216 organisms, suggesting those paints could be a viable alternative for manual scrubbing of cages

217 when conducting short-term settlement experiments. In contrast, settlement to tiles inside cages

218 treated with the ecofriendly paint had significantly lower biomass and a different macrofouling

219 community composition compared to the scrubbed cages. Thus, using the ecofriendly paint as an

220 alternative to manual scrubbing in biological experiment apparatuses is not recommended.

221 The different macrofouling community structures and biomass of tiles inside the

222 ecofriendly painted cages suggests that the paint altered species composition and decreased

223 overall successful settlement on the tiles. While traditional copper-based ablative paints contain

224 harsh solvents, Hydrocoat $\mathrm{Eco}^{\circledR}$ is a water-based ablative paint and free of harsh solvents. It is

225 possible that the water in the ecofriendly antifouling paint caused the biocides to be dispersed

226 differently than those in the copper-based antifouling paints, which may have accounted for the

227 differences in recruitment, growth, and macrofouling community structure observed. It is also

228 important to consider that in addition to Econea ${ }^{\mathrm{TM}}$, there are other chemicals found within the

229 ecofriendly antifouling paint that may have contributed to the shift in macrofouling community

230 composition and reduction of biomass rendering the paint unsuitable for short-term settlement

231 experiments. The ecofriendly paint composition includes chemicals such as titanium dioxide,

232 zinc oxide, and zinc pyrithione. 
234 Karlsson \& Eklund, 2004) have been shown to be toxic to a variety of marine organisms. Zinc

235 oxide is typically used in conjunction with copper because it increases the toxicity of copper by

236 200-fold (Watermann et al., 2005). By itself, zinc oxide has a weak antifouling performance, but

237 there is concern that its presence in paints may cause future water quality issues (Watermann et

238 al., 2005; Holman et al., 2011). Although these chemicals are present in the ecofriendly paint we

239 used, the current study cannot determine whether any of them elicited the observed effects on

240 biomass and macrofouling community composition.

241 In addition to the differences in biomass and macrofouling community composition of

242 settlement to the tiles, the paints tested had varying success in product performance on the cages.

243 The copper-based painted cages performed well and retained negligible levels of biofouling

244 throughout the experiment and additional deployment times. Conversely, the performance of the

245 ecofriendly paint was relatively poor overall during the experiment. Specifically, during the

246 additional two-month deployment, the ecofriendly painted cages became partially covered with

247 turf algae dense enough on some parts of the cage to mask the blue paint color.

248 Although there is continued support and funding going into the development of

249 ecofriendly and alternative paints, the compounds Econea ${ }^{\mathrm{TM}}$, cappasicin, and medetomidine,

250 which are collectively referred to as "emerging" biocides, remain relatively unstudied (Thomas

251 \& Brooks, 2010; Guardiola et al., 2012; Gee et al., 2013). Assuming that a reduction in biomass

252 and a shift in macrofouling community composition is indicative of detrimental effects to the

253 local environment, the results of this study justify further investigation into the ecological

254 ramifications of Econea ${ }^{\mathrm{TM}}$ and other copper-free biocides.

255 The lack of local effects from the copper paints presented in this study contradicts 
256 previous research. For example, increased exposure to heavy metal pollution (i.e., International ${ }^{\circledR}$

257 Micron Extra 25-50\% cuprous oxide) has been shown to alter macrofouling community

258 composition and decrease native species densities, permitting the dominance of more tolerant,

259 non-indigenous ones (Piola \& Johnston, 2007). Canning-Clode et al. (2011) found that as

260 exposure to antifouling paint increased, community composition changed and the densities

261 decreased for both native and non-indigenous species. However, it should be noted that Canning-

262 Clode et al. (2011) used paint with much higher copper concentrations (i.e., Interlux ${ }_{\circledast}$ Ultra-Kote

$26376 \%$ cuprous oxide) than what was used in the present study. It is possible that the decreased

264 levels of copper in the present study did not surpass organismal tolerances, thus the observed

265 lack of local negative effects. Furthermore, Canning-Clode et al. (2011) exposed the marine

266 communities to various copper concentrations by painting borders with different loads of

267 antifouling paint around the biofouling communities. This direct contact, versus the $5 \mathrm{~cm}$ buffer

268 used here, may also explain why macrofouling community compositions of the copper paint

269 treatments did not differ from the scrubbed-cage treatment. It is also possible that disparity in

270 deployment time may account for the differences between previous studies and the present study,

271 since that by Piola and Johnston (2007) lasted seven months and Canning-Clode et al. (2011)

272 lasted nine weeks.

273 The copper-based ablative paints were manufactured to last for approximately 12 months

274 and require physical abrasion by water in high vessel velocities or manual removal by methods

275 such as power washing for paint layers to ablate. It is likely that due to the short duration of the

276 study and the location of the experiment (i.e., protected waters in a harbor), the paints did not

277 experience forces strong enough to consistently ablate, thus the observed lack of an effect on the

278 tile within the cage. However, small specs of the copper-based paints were occasionally observed 
279 on the tiles, yet the direct contact with the paint particulates did not affect the biomass and

280 composition of the communities on tiles in the reduced-copper painted cages. Further studies can

281 expand on the present study's focus (i.e., short-term settlement patterns and trends) to test the

282 effects of reduced-copper paints on biological and/or ecological process beyond settlement.

283 Although it was not tested in the present study, the potential of bioaccumulation of heavy metals

284 may pose serious problems to studies that measure growth, survival, or other biological and

285 ecological processes over longer periods of time that those measured here (Bao et al., 2010; Qi et 286 al., 2013).

The observed effects on tiles in the no-cage and no-scrub treatments were expected. The distinct macrofouling community, biomass, and percent cover observed in the no-cage treatment can be attributed to the signs of grazing from local predators such as the common Sheepshead 290 (Archosargus probatocephalus; JJ Walbaum). Additionally, the distinct macrofouling

291 community and decreasing rate of biomass accumulation in the no-scrub treatment was likely

292 due to biofouling buildup on the cage that subsequently obstructed water flow and settlement on

293 the tile within it. While the no-cage treatment was intended to reflect a common experimental

294 design used to separate pre- and post-settlement processes, the no-scrub treatment illustrated the 295 importance of accounting for biofouling of cage materials. Addressing biofouling using the 296 traditional approach of frequent manual removal will likely continue to be the primary method 297 employed by field scientists, but doing so is not always logistically feasible. The newly 298 developed reduced-copper antifouling paint compositions, such as those used here, have the 299 potential to act as a viable alternative for manual maintenance of infrastructures, such as cages. 


\section{ACKNOWLEDGMENTS}

301 We thank Bill Wolf from Pettit Paint, who graciously donated the three antifouling paints to our

302 research and provided feedback on product performance. Owen Stokes-Cawley and Matthew

303 Farnum helped with fieldwork and data collection and Jonathan Grabowski provided helpful

304 feedback and editorial assistance. This research was in partial fulfillment of a masters degree

305 conferred to A.S.J. from the Three Seas Program at Northeastern University.

306

307

\section{REFERENCES}

308

309

310

311

Bao W-Y, Lee O-O, Chung H-C, Li M, Qian P-Y. 2010. Copper affects biofilm inductiveness to larval settlement of the serpulid polychaete Hydroides elegans (Haswell). Biofouling 26:119-128. DOI: 10.1080/08927010903329680

Burkepile DE, Hay ME. 2010. Impact of herbivore identity on algal succession and coral growth on a Caribbean reef. PLoS One 5:e8963. DOI:10.1371/journal.pone.0008963.

Burkholder DA, Heithaus MR, Fourqurean JW, Wirsing A, Dill LM. 2013. Patterns of top-down control in a seagrass ecosystem: could a roving apex predator induce a behaviour-mediated trophic cascade? Journal of Animal Ecology 82:1192-1202. DOI: $10.1111 / 1365-2656.12097$.

Canning-Clode J, Fofonoff P, Riedel GF, Torchin M, Ruiz GM. 2011. The effects of copper pollution on fouling assemblage diversity: a tropical-temperate comparison. PLoS One 6:e18026. DOI: 10.1371/journal.pone.0018026.

Dobretsov S, Williams DN, Thomason JC. 2014. Biofouling methods: John Wiley \& Sons. Fitridge I, Dempster T, Guenther J, de Nys R. 2012. The impact and control of biofouling in 
marine aquaculture: a review. Biofouling 28:649-669. DOI:

323 10.1080/08927014.2012.700478.

324 Gee D, Grandjean P, Hansen SF, van denHove S, MacGarvin M, Martin J, Nielsen G, Quist D,

325 Stanners D. 2013. Late lessons from early warnings: science, precaution, innovation.

326 European Environment Agency.

327 Guardiola FA, Cuesta A, Meseguer J, Esteban MA. 2012. Risks of using antifouling biocides in 328 aquaculture. International journal of molecular sciences 13:1541-1560. DOI:

329 10.3390/ijms13021541.

330

Holman KL, Bauer S, D’Anna H, Engel J, Habib J, Wolf K, Schottle R, Halston A, Villasenor A, 2011. Safer alternatives to copper antifouling paints for marine vessel. Available at https://www.portofsandiego.org/public-documents/cat_view/157environment/438-copper-reduction-program/442-monitoring-and-data-assessment/443epa-funded-qsafer-alternatives-to-copper-based-antifouling-paintsq-project.html (accessed 1 October 2015)

Jompa J, McCook LJ. 2002. Effects of competition and herbivory on interactions between a hard coral and a brown alga. Journal of experimental marine biology and ecology 271:25-39. DOI: 10.1016/S0022-0981(02)00040-0.

Karlsson J, Eklund B. 2004. New biocide-free anti-fouling paints are toxic. Marine pollution bulletin 49:456-464. DOI: 10.1016/j.marpolbul.2004.02.034.

Kobayashi N, Okamura H. 2002. Effects of new antifouling compounds on the development of sea urchin. Marine pollution bulletin 44:748-751. DOI: 10.1016/S0025-326X(02)00052-8

Kohler KE, Gill SM. 2006. Coral Point Count with Excel extensions (CPCe): A Visual Basic program for the determination of coral and substrate coverage using random point count 
methodology. Computers \& Geosciences 32:1259-1269.

347 Piola RF, Johnston EL. 2008. Pollution reduces native diversity and increases invader dominance in marine hard-substrate communities. Diversity and Distributions 14:329-342. DOI: $10.1111 / \mathrm{j} .1472-4642.2007 .00430 . \mathrm{x}$

Qi L, Wang Y, Sha J, Wang Y, Tang X. 2015. The toxic effects of copper on larvae of the

Sharma VK. 2009. Aggregation and toxicity of titanium dioxide nanoparticles in aquatic environment - a review. Journal of Environmental Science and Health Part A 44:14851495. DOI: $10.1080 / 10934520903263231$.

Simpson SL, Spadaro DA, O’Brien D. 2013. Incorporating bioavailability into management barnacle species Chthamalus challengeri. Chinese Journal of Oceanology and Limnology limits for copper in sediments contaminated by antifouling paint used in aquaculture.

Sokal RR, Rohlf FF, 1981. Biometry: the principles and practice of statistics in biological research. New York: W.H. Freeman.

364 Thomas K, Brooks S. 2010. The environmental fate and effects of antifouling paint biocides. Biofouling 26:73-88. DOI: 10.1080/08927010903216564. 
366 Watermann, BT, Daehne B, Sievers S, Dannenberg JC, Klijnstra JW, Heemken O. 2005.

367 Bioassays and selected chemical analysis of biocide-free antifouling coatings. Chemosphere 60: 1530-1541. DOI: 10.1016/j.chemosphere.2005.02.066

369 Woods Hole Oceanographic Institution. 1952. Marine fouling and its prevention: United States 370 Naval Institute.

371 Yebra DM, Kiil S, Dam-Johansen K. 2004. Antifouling technology—past, present and future steps towards efficient and environmentally friendly antifouling coatings. Progress in organic coatings 50:75-104. DOI: 10.1016/j.porgcoat.2003.06.001

374 
Figure 1

Multiple views of an exclusion cage.

Photographs of an exclusion cage with a suspended settlement tile viewed from the top (A), front (B), and side (C).
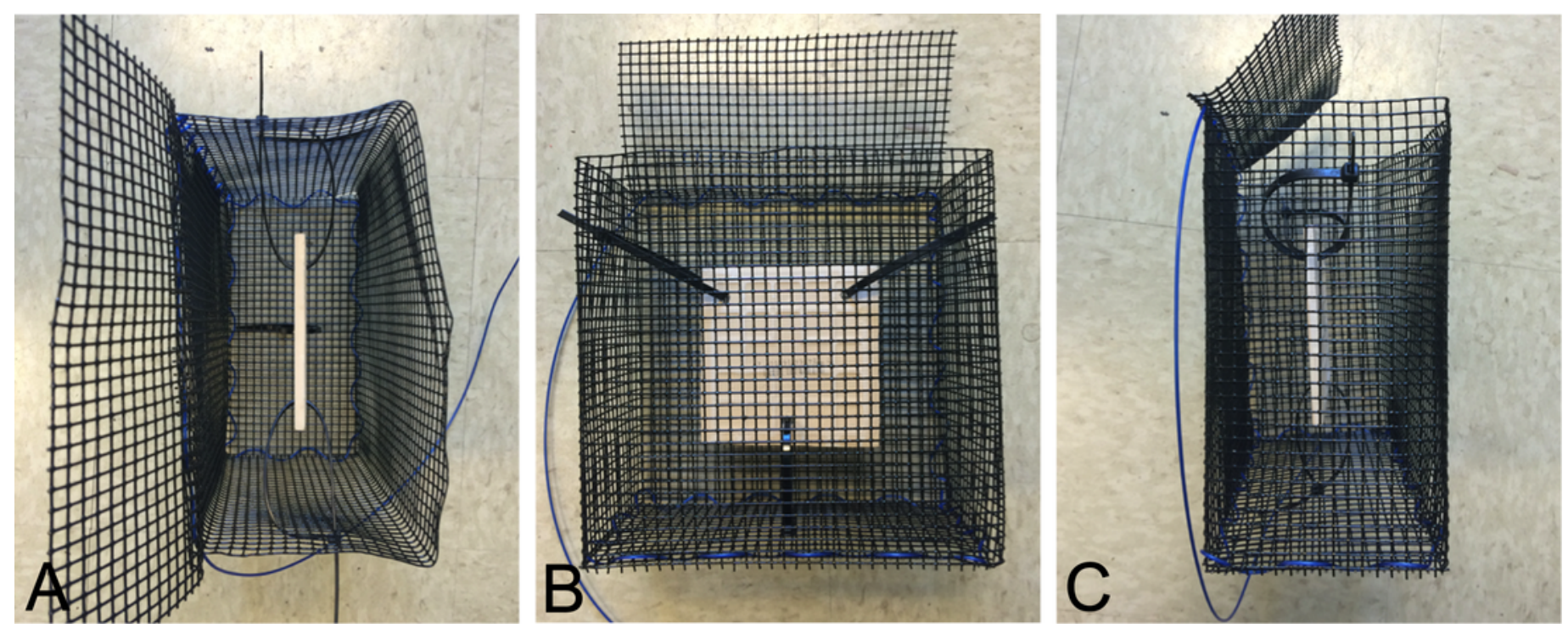
Figure 2 (on next page)

Percent cover of macrofouling organisms on settlement tiles.

Percent cover (mean $\pm 1 \mathrm{SE}$ ) of the four primary macrofouling organisms on settlement tiles on day 42 across treatments. The primary macrofouling organisms consisted of "turf algae" $(A)$, barnacles (B), oysters (C), and tubeworms (D). Treatment labels are: 1) no-scrub, 2) scrub, 3) ecofriendly, 4) $\left.21 \% \mathrm{Cu}_{2} \mathrm{O}, 5\right) 40 \% \mathrm{Cu}_{2} \mathrm{O}$, and 6) no-cage control. 

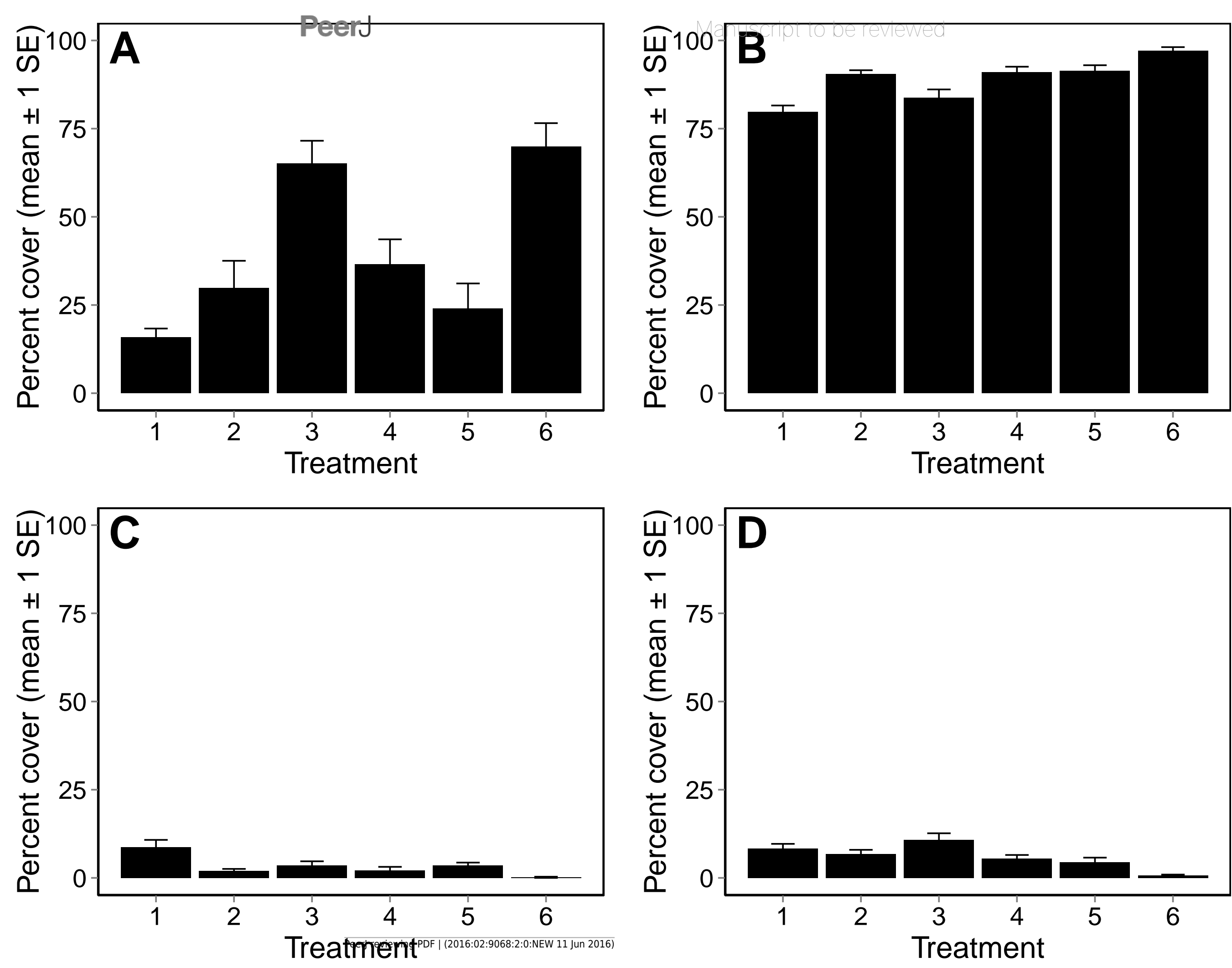


\section{Figure 3 (on next page)}

Community composition of settlement tiles.

Nonmetric multidimensional scaling (nMDS) of community composition among the six experimental treatments. Minimum convex polygons and associated letter groupings (i.e., A,

$B, C, D)$ indicate differences among treatments according to the PERMANOVA and subsequent pairwise comparisons. 


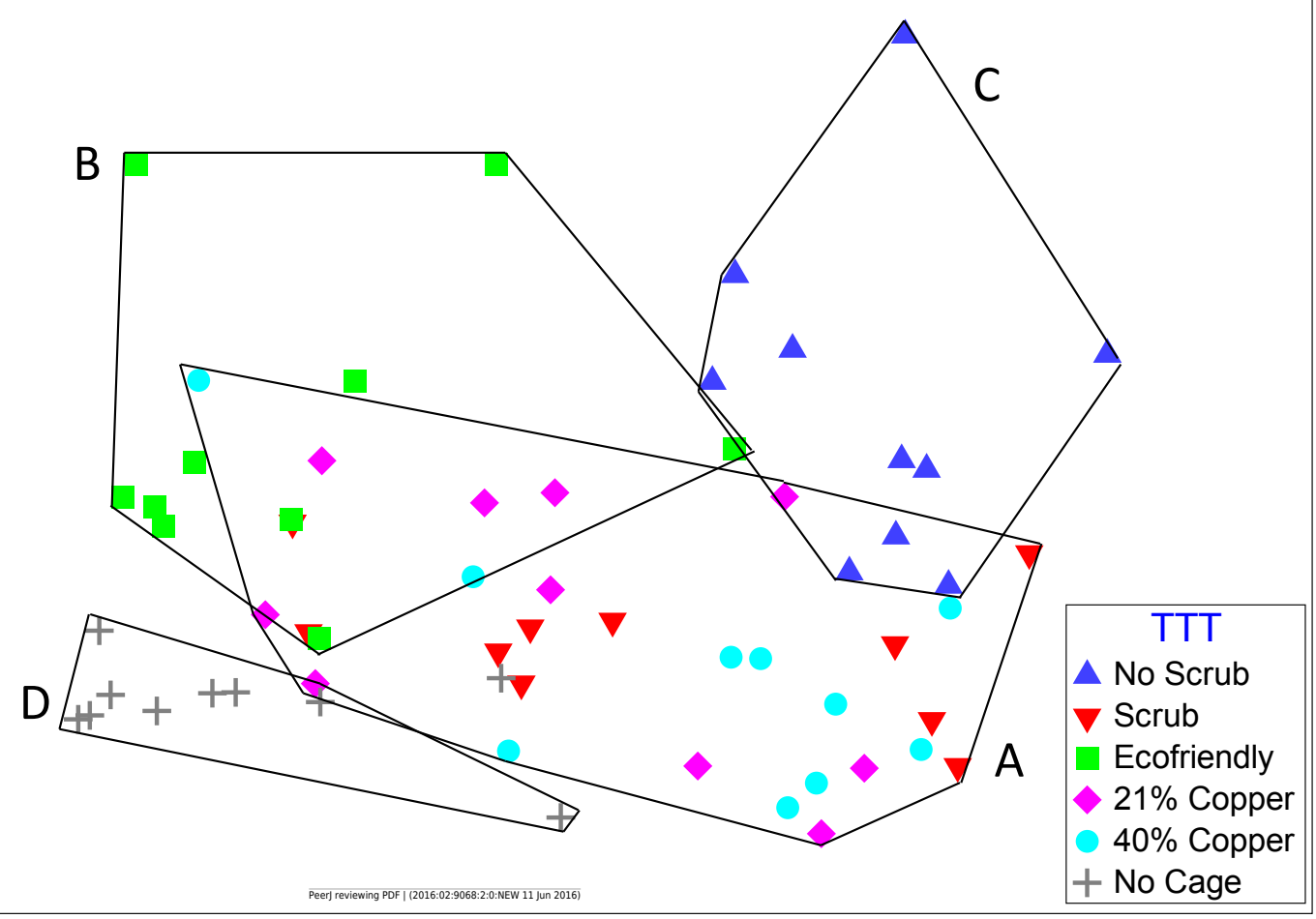




\section{Figure 4 (on next page)}

Settlement tile biomass as a function of treatment and day.

Total biomass accumulation (mean $\pm 1 \mathrm{SE}$ ) on settlement tiles measured weekly for six weeks across the six experimental treatments. Significant differences among treatments according to Tukey HSD $(p<0.05)$ are indicated on the plot with different letters (i.e., A, B, C, D). 


\section{Figure 5}

Photographs of post experiment exclusion cages.

Experimental cages after the additional two-month deployment following the primary sixweek experiment. Biofouling on cages with copper-based paints remained low $(A)$ while turf algae tended to cover those treated with ecofriendly paints (B). Left unattended, continued settlement to and growth on tiles filled the exclusion cages treated with $21 \% \mathrm{Cu}_{2} \mathrm{O}$ (C) and $40 \% \mathrm{Cu}_{2} \mathrm{O}$ paints (D). 

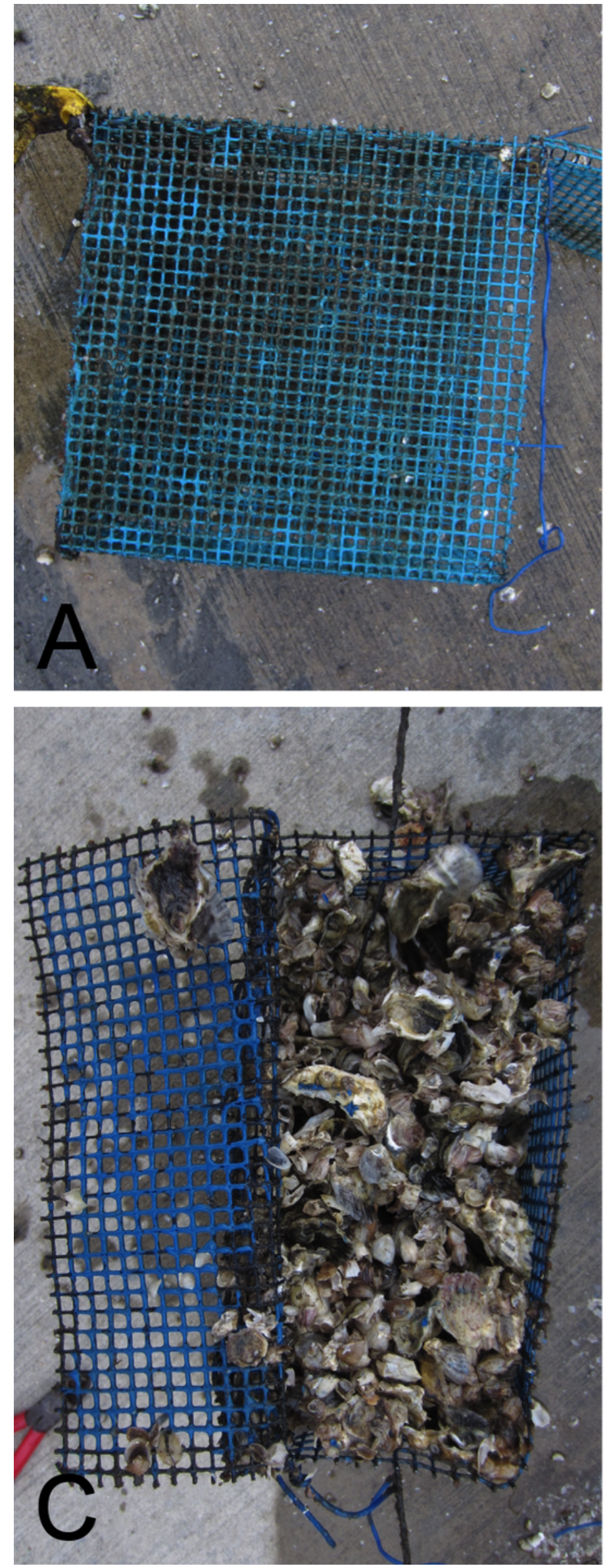
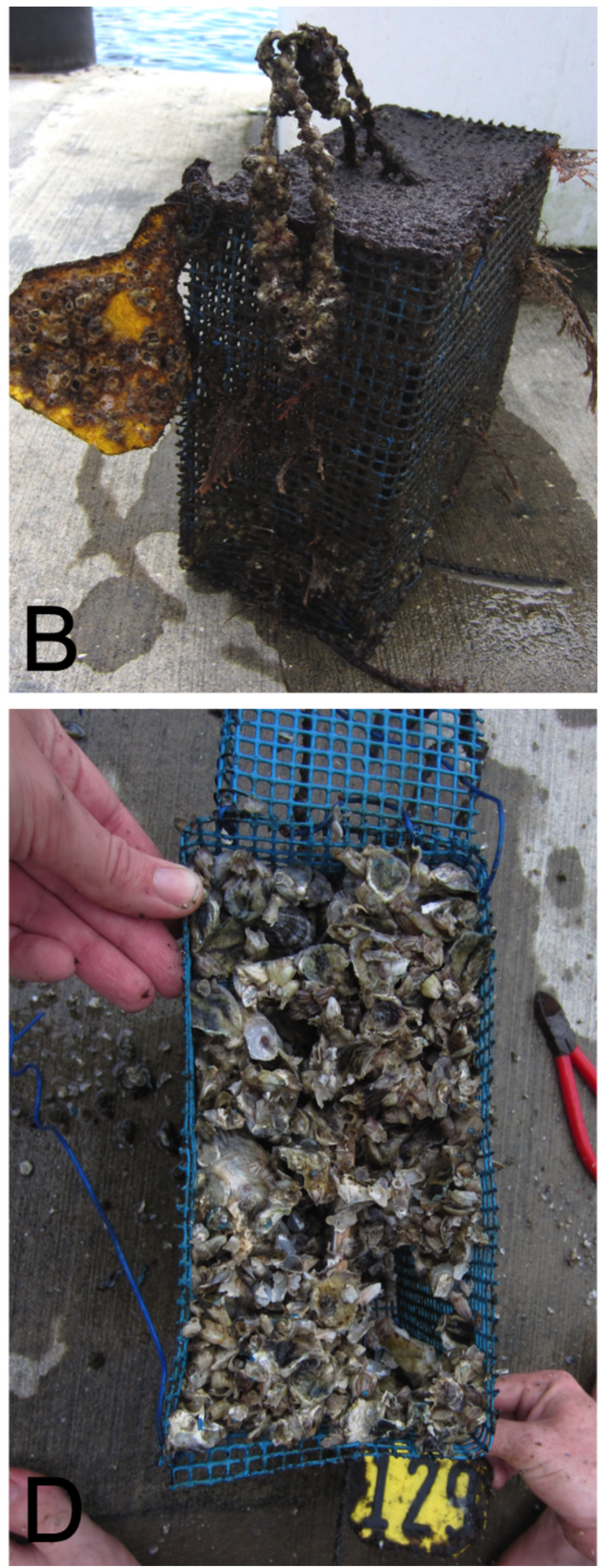


\section{Figure 6 (on next page)}

Settlement tile percent cover as a function of treatment and day.

Total percent cover (mean $\pm 1 \mathrm{SE}$ ) on settlement tiles measured weekly for six weeks across the six experimental treatments. 


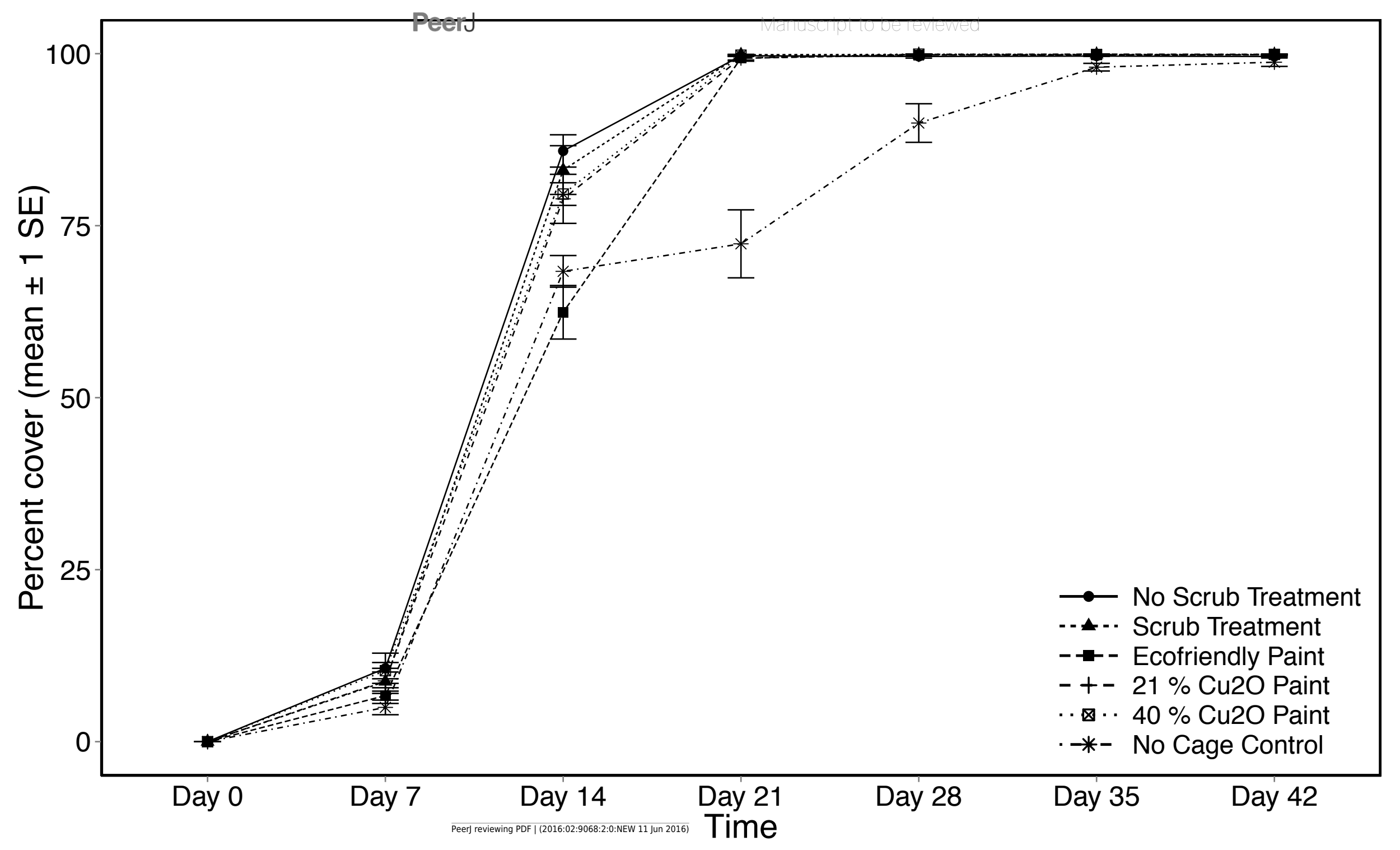




\section{Table $\mathbf{1}$ (on next page)}

Species presence across treatments and day.

Species presence (indicated with "*") as a function of treatment and day of study. Treatment labels are: 1) no-scrub, 2) scrub, 3) ecofriendly, 4) $21 \% \mathrm{Cu}_{2} \mathrm{O}$, 5) $40 \% \mathrm{Cu}_{2} \mathrm{O}$, and 6) no-cage control. Mussels (Perna viridis and Geukensia granosissima) were indistinguishable within the first six weeks of the experiment. 


\begin{tabular}{|c|c|c|c|c|c|c|c|c|c|c|c|c|c|c|c|c|c|c|c|c|c|c|c|c|c|c|c|c|c|c|c|c|c|c|c|c|}
\hline & \multicolumn{6}{|c|}{ Day 7} & \multicolumn{6}{|c|}{ Day 14} & \multicolumn{6}{|c|}{ Day 21} & \multicolumn{6}{|c|}{ Day 28} & \multicolumn{6}{|c|}{ Day 35} & \multicolumn{6}{|c|}{ Day 42} \\
\hline Treatment & 1 & 2 & 3 & 4 & 5 & 6 & 1 & 2 & 3 & 4 & 5 & 6 & 1 & 2 & 3 & 4 & 5 & 6 & 1 & 2 & 3 & 4 & 5 & 6 & 1 & 2 & 3 & 4 & 5 & 6 & 1 & 2 & 3 & 4 & 5 & 6 \\
\hline A. amphitrite & $*$ & $*$ & $*$ & $*$ & * & $*$ & * & * & $*$ & $*$ & $*$ & $*$ & $*$ & $*$ & $*$ & $*$ & $*$ & $*$ & * & $*$ & $*$ & * & $*$ & $*$ & $*$ & $*$ & $*$ & $*$ & $*$ & $*$ & * & $*$ & $*$ & $*$ & $*$ & $*$ \\
\hline C. virginica & & & & & & & & & & & & & & & & & & & $*$ & $*$ & & & * & & $*$ & $*$ & $*$ & $*$ & $*$ & & $*$ & $*$ & $*$ & $*$ & $*$ & $*$ \\
\hline Hydroides spp. & $*$ & $*$ & & & & & * & * & $*$ & $*$ & $*$ & $*$ & $*$ & $*$ & * & $*$ & $*$ & $*$ & $*$ & $*$ & $*$ & * & $*$ & & $*$ & $*$ & * & $*$ & $*$ & & $*$ & $*$ & $*$ & $*$ & $*$ & $*$ \\
\hline Mussel spp. & & & & & & & & & & & & & $*$ & & $\uparrow$ & & & & & & & & & & & & & & & & $*$ & $*$ & $*$ & $*$ & $*$ & \\
\hline Turf algae & $*$ & $*$ & $*$ & $*$ & $*$ & $*$ & $*$ & $*$ & $*$ & $*$ & $*$ & $*$ & $*$ & $*$ & $*$ & $*$ & $*$ & $*$ & $*$ & $*$ & $*$ & $*$ & $*$ & $*$ & $*$ & $*$ & $*$ & $*$ & $*$ & * & $*$ & $*$ & $*$ & $*$ & $*$ & $*$ \\
\hline
\end{tabular}

